\title{
- 545 - Artigo Original \\ O COMPORTAMENTO DE PROSTITUTAS EM TEMPOS DE AIDS E OUTRAS DOENÇAS SEXUALMENTE TRANSMISSÍVEIS: COMO ESTÃO SE PREVENINDO?
}

\author{
Ana Débora Assis Moura ${ }^{1}$, Rodisheily Maria Silva de Oliveira², Guldemar Gomes de Lima ${ }^{3}$, Leiliane Martins \\ Farias $^{4}$, Aline Rodrigues Feitoza ${ }^{5}$
}

\footnotetext{
${ }^{1}$ Mestre em Enfermagem pela Universidade Federal do Ceará (UFC). Enfermeira da Estratégia Saúde da Família (ESF) do município de Fortaleza-CE. Docente da Faculdade Integrada da Grande Fortaleza. Ceará, Brasil. E-mail: anadeboraam@ hotmail.com

${ }^{2}$ Enfermeira da ESF do município de Miraíma-CE. Ceará, Brasil. E-mail: sheily_oliver@hotmail.com.

${ }^{3}$ Enfermeiro. Especialista em Saúde da Família.Email: guldemar@hotmail.com.

${ }^{4}$ Doutoranda em Enfermagem pela UFC. Docente da Faculdade Metropolitana de Fortaleza. Ceará, Brasil. E-mail: leiliane. martins@hotmail.com

${ }^{5}$ Doutora em Enfermagem. Docente da Universidade de Fortaleza. Ceará, Brasil. E-mail: alinerfeitoza@hotmail.com
}

RESUMO: Este estudo teve como objetivo verificar o comportamento de prostitutas quanto à prevenção de doenças sexualmente transmissíveis e da aids, bem como investigar como estão se prevenindo das mesmas. Trata-se de uma pesquisa exploratória, de abordagem qualitativa, realizada na Associação das Prostitutas do Ceará, em setembro de 2008, através de questionário, com 25 prostitutas. Os dados foram analisados através da análise de conteúdo, após serem agrupados em quatro categorias: conhecimento sobre doenças sexualmente transmissíveis/aids; vivência com a(s) doença(s); prevenção da doenças sexualmente transmissíveis/aids; e uso de drogas. Concluiu-se que as prostitutas não fazem uso de preservativo em todas as relações sexuais, portanto, as doenças transmitidas pelo sexo representam uma realidade. A desinformação sobre a(s) doença(s) é notável. O consumo de drogas lícitas e ilícitas é frequente entre elas, fator que expõe a situações mais vulneráveis com relação ao HIV/aids.

DESCRITORES: Mulher. Prostituição. Doenças sexualmente transmissíveis. Síndrome da Imunodeficiência Adquirida.

\section{PROSTITUTE BEHAVIOR IN TIMES OF AIDS AND OTHER SEXUALLY TRANSMITTED DISEASES: HOW ARE THEY PROTECTING THEMSELVES?}

\begin{abstract}
The objective of this study is to verify the behavior of prostitutes concerning preventing sexually transmitted diseases and AIDS, as well as to investigate how they protect themselves from these diseases. This is an exploratory research using a qualitative approach, carried out at the Association of Prostitutes in Ceará, Brazil, in September of 2008 through a questionnaire completed by 25 prostitutes. The data was analyzed through content analysis after being grouped into four categories: knowledge about sexually transmitted diseases/AIDS; living experience with the disease(s); preventing sexually transmitted diseases/AIDS; and drug use. It was concluded that the prostitutes do not use condoms in all their sexual relations, so sexually transmitted diseases represent a reality; that misinformation about the disease is remarkable; and that the consumption of licit and illicit drugs is common among them, a factor that exposes the most vulnerable situations related to HIV/AIDS.
\end{abstract}

DESCRIPTORS: Woman. Prostitution. Sexually transmitted diseases. Acquired Immune Deficiency Syndrome.

\section{EL COMPORTAMIENTO DE LAS PROSTITUTAS EN TIEMPOS DE SIDA Y OTRAS ENFERMEDADES DE TRANSMISIÓN SEXUAL: ¿CÓMO SE PREVIENEN?}

RESUMEN: Este estudio tuvo como objetivo verificar el comportamiento de las prostitutas en relación a la prevención de enfermedades de transmisión sexual y del Síndrome de Inmunodeficiencia Adquirida-SIDA, así como investigar cómo se previenen de esas enfermedades. Se trata de una investigación exploratoria, con enfoque cualitativo, llevada a cabo en la Asociación de las Prostitutas en Ceará, Brazil, en septiembre de 2008, a través de una encuesta con 25 prostitutas. El análisis de los datos se hizo según el análisis de contenido, después de ser agrupados en cuatro categorías: conocimiento sobre las enfermedades de transmisión sexual/SIDA; convivencia con la(s) enfermedad(es); prevención de la enfermedad de transmisión sexual/SIDA; y el uso de drogas. Se concluyó que las prostitutas no usan preservativos en todas las relaciones sexuales, por lo tanto, las enfermedades de transmisión sexual representan una realidad; la desinformación sobre la(s) enfermedad(es) es notable; el consumo de drogas lícitas e ilícitas es frecuente entre ellas, factor que las expone a situaciones más vulnerables con relación al VIH/SIDA.

DESCRIPTORES: Mujer. Prostitución. Enfermedades de transmisión sexual. Síndrome de Inmunodeficiencia Adquirida. 


\section{INTRODUÇÃO}

Com o surgimento e a difusão dos métodos contraceptivos, as mulheres viram o exercício da sexualidade desvinculado da reprodução. A relação sexo e reprodução sempre foi culturalmente transmitida ao longo de vários anos. Apesar disso, a prostituição é uma das profissões conhecidas desde a antiguidade, que busca pelo prazer através do sexo. ${ }^{1-2}$

Em detrimento disso, foi constituído um vínculo, mais metafórico do que factual, entre a transmissão de doenças sexualmente transmissíveis e a prostituição. ${ }^{1-2}$ Tentativas de controle da prostituição foram implementadas no passado, variando entre a satanização, isto é, do controle exercido pela instituição religiosa, passando pela proibição expressa em códigos civis e chegando aos dias atuais no Brasil, mesmo que ainda rodeada de preconceitos e estigmas, e a demanda pela sua legalização, como atividade profissional.

Apesar das mudanças ocorridas nos costumes sociais ao longo dos anos, as prostitutas ainda são vítimas de preconceitos, constituindo um grupo excluído socialmente. Muitas vezes não são contempladas com ações governamentais que favoreçam suas principais reivindicações, como a oferta de melhor qualidade de vida para elas. ${ }^{1}$

Atualmente, embora existam associações de prostitutas em quase todos os estados brasileiros e em muitos países do mundo inteiro e se considere a prostituição como profissão, esta ainda constituise de muitos preconceitos, que faz da profissão uma marca social, com rejeição por grande parte da sociedade.

Com relação às infecções transmitidas pelo sexo, as Doenças Sexualmente Transmissíveis (DSTs) ainda são um grave problema de saúde pública. A Organização Mundial de Saúde (OMS) estima que ocorram, no mundo, cerca de 340 milhões de casos de DSTs por ano. Nessa estimativa não estão incluídos a herpes genital e o Vírus do Papiloma Humano ou Condiloma Acuminado - VPH ou HPV, pois segundo o Ministério da Saúde, cerca de 12 milhões de pessoas adquirem uma DSTs por ano. ${ }^{3}$

Em relação à aids, de 1980 a junho de 2008, foi identificado um total de 506.499 casos no Brasil. Em 2006, considerando dados preliminares, foram registrados 35.459 casos da doença, confirmando uma tendência de queda no número de casos, identificada a partir de 2002, quando houve 38.816 casos notificados. Em 2005, a taxa foi de 19,5/100 mil e em 2006, de 19/100 mil. De acordo com o relatório do
Programa Conjunto das Nações Unidas sobre Vírus da Imunodeficiência Humana (HIV) ou Síndrome da Imunodeficiência Adquirira - aids (UNAIDS), estima-se que existam, atualmente, 33,2 milhões de pessoas infectadas com o HIV em todo o mundo, e que ocorreram 2,5 milhões de novas infecções em 2007. Considerando as regiões do Brasil, houve 18.155 casos identificados na região Norte $(4 \%)$; 58.348 , na Nordeste $(12 \%)$; 305.725, na Sudeste (60\%); 95.552, na Sul (19\%); e 28.719, na Centro-Oeste (6\%). Quanto ao sexo, foram identificados 333.485 casos de aids no sexo masculino e 172.995 no sexo feminino. Observou-se que a razão de sexo (M:F) no Brasil vem diminuindo ao longo da série histórica, passando de 15,1:1, em 1986, para1,5:1, em 2006. ${ }^{4}$

Através dos dados epidemiológicos, constatou-se que a aids está cada vez mais presente na vida das mulheres, sendo as prostitutas ainda mais vulneráveis às DSTs/aids, pois o sexo faz parte do cotidiano delas, como profissão.

As prostitutas estão sujeitas a um maior risco de contrair uma DSTs, pois trabalham diariamente com diversos clientes, com histórias sexuais desconhecidas. Elas integram um grupo que necessita de uma educação sexual elucidativa com o desígnio de abordar a prevenção para uma prática sexual segura, pois as prostitutas devem ter conhecimento sobre a importância do uso do preservativo para a segurança em saúde, já que é considerado um dos métodos mais eficazes na prevenção das DSTs/ aids, desde que seja usado de maneira adequada e em todas as relações sexuais. ${ }^{5-6,8}$

A aids e as DSTs tornaram-se para as prostitutas um risco decorrente do seu trabalho, uma vez que o sexo é a sua matéria-prima. Deste modo, o preservativo representa segurança para que a profissional possa se prevenir das DSTs, portanto um objeto fundamental e indispensável para o exercício dessa profissão. ${ }^{6,7,8}$

Conforme a Associação das Prostitutas do Ceará (APROCE), cerca de 90\% das prostitutas cadastradas usam preservativo com os clientes e não realizam "programa" sem proteção. Entretanto, quando se trata de namorado, amante ou parceiro fixo, a maioria não usa. ${ }^{7}$

Portanto, este estudo é de grande relevância para os profissionais de saúde, as prostitutas, a comunidade científica e a sociedade como um todo, pois todos estão sujeitos a contrair DSTs, desde que não se previnam adequadamente.

Devido ao grande número de pessoas infectadas por DST, e estas ainda são consideradas um risco existencial, houve o interesse de conhecer 
como as prostitutas em Fortaleza estão se comportando frente às DSTs/aids, quais os conhecimentos adquiridos acerca do assunto e se elas estão usando preservativo em todas as relações sexuais.

A partir desses questionamentos, este estudo objetivou verificar o comportamento de prostitutas quanto a prevenção de DSTs e da Síndrome da Imunodeficiência Adquirida - aids, bem como investigar como estão se prevenindo das mesmas.

\section{METODOLOGIA}

Trata-se de uma pesquisa do tipo exploratória, que pretendeu observar, descrever e documentar os aspectos situacionais da prostituição, de abordagem qualitativa, na qual aponta que os conhecimentos sobre os indivíduos somente são possíveis com a descrição da experiência humana, tal como é vivida e definida por seus próprios agentes. ${ }^{9}$ Foi realizada na APROCE, em FortalezaCE. A APROCE foi criada em 13 de novembro de 1990 e desenvolve um trabalho educativo sobre prevenção da aids e sexualidade com prostitutas e adolescentes, orienta as prostitutas sobre a importância do uso do preservativo na prevenção da aids e de outras DSTs, realiza oficinas sobre sexo seguro e capacitação em casas e pontos de prostituição da capital e do interior. Além da distribuição de preservativos, divulga algumas técnicas alternativas de inserção destes. ${ }^{7}$

Os sujeitos do estudo foram 25 prostitutas, cadastradas na Associação, e que trabalham diariamente em praças, bares e bordéis da capital de Fortaleza. A escolha das participantes foi aleatória, e as mesmas concordaram espontaneamente em participar da pesquisa.

A coleta de dados foi realizada através de questionário, em setembro de 2008. Foram realizadas três visitas na Associação, no momento em que as prostitutas participavam de atividades educativas. As pesquisadoras convidaram as mulheres a participarem da pesquisa, leram o Termo de Consentimento Livre e Esclarecido (TCLE), esclareceram todas as dúvidas que surgiram, e entregaram o questionário e o TCLE a todas as prostitutas que concordaram em participar do estudo, totalizando 25 mulheres. As prostitutas responderam ao questionário de próprio punho, devolvendo-o posteriormente às pesquisadoras, juntamente com o TCLE. O questionário constou de questões fechadas (dados de identificação e dados sociodemográficos) e questões abertas (conhecimentos sobre DSTs/aids; comportamentos sexuais; tipos de relacionamentos com clientes, namorados ou companheiros; quanto ao uso de drogas; o que fazer num caso de uma DSTs; quais os meios utilizados para o tratamento de uma possível DSTs). Foi realizada na própria APROCE, por ser o local mais acessível para as pesquisadoras e prostitutas, além da abrangência maior de mulheres em um único espaço.

As respostas das mulheres foram organizadas em quatro categorias: conhecimento sobre DSTs/aids, vivência com as DSTs/aids, prevenção das DSTs/aids; , e uso de drogas. Foram analisadas través da análise de conteúdo, que apresenta três fases para uma análise eficiente: a) as categorias surgiram para se estabelecer classificações, agrupar elementos, idéias ou expressões em torno de um assunto; b) o estabelecimento da compreensão dos dados coletados, podendo confirmar ou não os pressupostos da pesquisa, respondendo ou não às questões formuladas; e c) a ampliação do conhecimento sobre o assunto pesquisado, articulando ao seu contexto cultural. ${ }^{10}$

Os princípios éticos foram respeitados em todas as fases do estudo, em consonância com o que preconiza a Resolução n ${ }^{\circ} 196 / 96$. O estudo foi aprovado pelo Comitê de Ética em Pesquisa, da Faculdade Integrada do Ceará (FIC), sob o protocolo de $n^{\circ}$ 070/08.

As participantes do estudo foram orientadas sobre o anonimato, por isso foram utilizadas siglas em ordem crescente: entrevistada 1 a entrevistada 25 (e1...e25). Assinaram o TCLE e tiveram a liberdade de retirar seu consentimento em qualquer momento e deixar de participar da pesquisa.

\section{APRESENTAÇÃO E ANÁLISE DOS RE- SULTADOS}

\section{Caracterização do perfil da clientela}

A faixa etária das prostitutas variou de 13 a 37 anos sendo que 19 encontram-se na faixa etária de 16 a 25 anos. Percebeu-se o predomínio de uma faixa etária mais jovem e produtiva no ramo da prostituição. Sabe-se que a jovem entra na prostituição com vistas a melhores rendimentos e para a maior aquisição de bens de consumo, e condições que permitam uma melhor sobrevivência. ${ }^{11}$

Quanto ao estado civil, as mulheres dividiram-se em: 19 solteiras; três casadas; duas separadas e uma viúva. A maioria das mulheres casadas que se prostitui esconde sua condição de seu marido ou companheiro, fazendo-se passar por outra profissional, como empregada doméstica, vende- 
dora, dentre outras. Em outras circunstâncias, o companheiro sabe da prostituição da mulher, mas não se incomoda, e faz "vista grossa", pois esta é, muitas vezes, arrimo familiar. ${ }^{12}$

Em relação ao nível de escolaridade das mulheres, destaca-se uma incidência maior (15) das que concluíram ou estão em conclusão do ensino fundamental. Contudo apenas uma delas iniciou curso universitário.

O baixo nível de escolaridade, as dificuldades financeiras ou a pobreza absoluta, compõem os obstáculos para a integração das prostitutas no mercado de trabalho. Para aquelas que pertencem às classes mais baixas, as perspectivas de mudança de atividade ainda são menos viáveis em virtude da baixa escolaridade e da ausência de qualificação profissional.

As adolescentes ingressam na prostituição principalmente devido à violência sexual e/ou doméstica sofrida, agravada pela situação socioeconômica precária de suas famílias, caracterizando sua exclusão na sociedade (escola, consumo, mercado de trabalho, saúde e cultura). ${ }^{8}$

Quanto à naturalidade, todas eram naturais do Estado do Ceará, vinte da capital, Fortaleza, e cinco delas da região metropolitana do Estado.

\section{O conhecimento sobre DSTs/aids}

Foi verificado conhecimento superficial sobre algo que é imprescindível à sua profissão. Demonstraram ter pouco conhecimento sobre as DSTs e a aids. De forma a preservar a clientela e a própria sobrevivência, as DSTs se apresentam para elas como doenças do "outro", colocando-se distante da sua prática pessoal ou profissional. É uma doença que pega do homem (e1). São doenças pegas pelo sexo e que matam (e2). Virus que causa a morte (e3).

As respostas revelaram que as prostitutas sabem o que são DSTs em geral, mas não têm conhecimento sobre a sintomatologia e as complicações de cada uma, especificamente. Além disso, também apresentaram conhecimento deturpado, como "doenças que pegam do homem", como se as mulheres também não pudessem transmiti-las; e "doenças que matam", como se todas as DSTs causassem a morte. As falas de muitas delas se relacionaram apenas ao HIV/aids, como a resposta da e3. Diante dessa realidade, faz-se necessário que as prostitutas ampliem de modo detalhado seus conhecimentos sobre as DSTs, já que o sexo faz parte do seu cotidiano, tornando-as universalmente mais vulneráveis que as outras pessoas.
A institucionalização de ações de prevenção das DSTs e da aids dirigidas às prostitutas, é necessária para assegurar a sustentabilidade e a ampliação dessas ações, evitando descontinuidade quando da restrição de recursos externos. O Poder Público deve assumir sua responsabilidade com a promoção da saúde e a prevenção das DSTs e da aids junto às prostitutas, devido à sua maior vulnerabilidade. ${ }^{13}$

O número de casos de DSTs vem aumentando nos últimos anos, sendo este um grave problema de Saúde Pública. O aumento ocorre principalmente em consequência das baixas condições socioeconômicas e culturais, das péssimas atuações dos serviços de saúde, do despreparo dos profissionais de saúde e de educação, e da falta de uma educação sexual adequada, principalmente voltada para os jovens. Hoje, as DSTs estão entre as doenças mais comuns em todo o mundo, estando entre as mais comuns a aids, a sífilis, a gonorréia e a clamídia. ${ }^{14}$

É importante e imprescindível que existam projetos educativos e de promoção à saúde voltados ao conhecimento e prevenção das DSTs, inclusive da aids. A APROCE tem como principal meta a mobilização de educadoras sociais com o objetivo de conscientizar homens e mulheres que se prostituem a prevenir-se das DSTs/aids. ${ }^{15}$

A APROCE exerce função representativa da classe das prostitutas no plano nacional e é protagonista de ações de prevenção em DST/aids, ação reconhecida pelo Ministério da Saúde, para prostitutas e seus respectivos parceiros.

A APROCE tenta exercer a cidadania em seu Estado, contribuindo com informações para as prostitutas, através de palestras, consultas e encaminhamento às Unidades de Saúde, desenvolve ações de prevenção, com distribuição de preservativos, assim como ações de intervenções com vínculos em projetos. Também conta com uma biblioteca para pesquisa, além de promover atividades profissionalizantes para a inserção no mercado de trabalho. Enfim, são inúmeros os benefícios prestados.

Mesmo com toda a divulgação existente nos dias de hoje, através de jornais, televisão, palestras, cursos e projetos destinados às prostitutas, a desinformação ainda é muito grande. As DSTs são conhecidas desde a antiguidade como doenças venéreas e eram tratadas com remédios caseiros. Os costumes antigos ainda estão entrelaçados na nossa cultura, mas a prostituta deve estar consciente dos meios de prevenção e seus tratamentos, e não deve deixar de usar o preservativo, por desculpa de não saber usá-lo, ou usá-lo de forma errônea. ${ }^{5}$ 


\section{A vivência com as DSTs/aids}

Quando indagado se alguma delas já havia contraído uma DSTs, 12 afirmaram que não e 13 confirmaram que já haviam apresentado ou que estavam tratando atualmente uma DSTs. Sim, herpes bucal, corrimentos, piolhos... (e4). Sim, sífilis (e5). Eu tenho aids (e6). Tenho sífilis, gonorréia e outras (e7).

A maioria das mulheres entrevistadas já teve ou tem uma DST, inclusive a aids. Isso corrobora estudos anteriores que revelam as DSTs como uma realidade na vida das prostitutas e que elas não estão utilizando o preservativo em todas as relações sexuais como deveriam. ${ }^{5,6}$

Este também é um grave problema de saúde pública, pois essas mulheres e provavelmente, seus parceiros/clientes, continuam disseminando doenças com outros prováveis parceiros. Portanto, comprova-se que o número de mulheres infectadas ainda é grande. A busca de afetividade nos relacionamentos, seja com o companheiro, namorado ou cliente fixo surge como possível fator impeditivo para adoção de comportamentos preventivos consistentes e seguros.

Um portador de DST tem mais chances de adquirir outras DSTs, inclusive a aids. O impacto que as DSTs causam à saúde da população é grande, principalmente na mulher infectada, que pode transmitir a doença ao parceiro e ao feto, se estiver grávida, ou ao recém-nascido. Porém, ao ser diagnosticada precocemente, a maioria das DSTs podem ser tratadas com eficácia, sem risco de complicações. ${ }^{16}$

O que mais acomete e incomoda as prostitutas portadoras de DST é a alteração da secreção vaginal, que surge em grande quantidade, com odor fétido. A presença de leucorréia com odor característico e prurido intenso constitui, na maioria dos casos, os principais sintomas associados aos processos inflamatórios das DSTs. Isso causa muito desconforto para a mulher, fazendo com que a mesma, muitas vezes, tenha que suspender sua atividade por um tempo. Além do desconforto físico, existe a questão financeira, que acaba por ser sentida pela mulher prostituta.

\section{A prevenção das DSTs/aids}

Algumas prostitutas relataram usar o preservativo em todas as relações sexuais, outras confirmaram que não o utilizam, e outras ainda que "às vezes". Sempre uso camisinha e sempre vou ao ginecologista (e8). Não, não uso (e9). Só usei depois que peguei as doenças (e10).
Verificou-se que algumas prostitutas estão conscientes da importância do uso do preservativo nas relações sexuais, como na resposta da e8; e mesmo que essa conscientização apenas tenha acontecido após a contaminação por uma DST, como na resposta da e10, outras ainda, não estão conscientes dessa importância de que o preservativo se trata de um instrumento para sua segurança, sendo indispensável para o exercício da sua profissão, como respondeu e9.

Desde o início da epidemia até os dias atuais, a Coordenação Nacional de DST e aids organizou várias campanhas de informação e prevenção, inseridas na mídia eletrônica e impressa, com o intuito de fortalecer ações de intervenção com um único propósito: conscientizar as pessoas quanto à importância de se prevenirem das DSTs/aids. As campanhas televisivas não foram produzidas diretamente para as mulheres que se prostituem, mas voltadas para as mulheres em geral. Porém, a inexistência de canais de comunicação de massa em regiões mais empobrecidas ou a pouca utilização do rádio na veiculação dessas campanhas, foram considerados indicadores da ineficácia dessa proposta, no que diz respeito ao acesso às informações pelas prostitutas. ${ }^{17}$

O preservativo é o método mais eficaz na prevenção das DSTs e até mesmo da aids, mas essa segurança depende do uso adequado e sistemático em todas as relações sexuais. ${ }^{6,18}$ Quando maior for o número de parceiros sexuais e sem proteção, maior será o risco de se contrair uma DST. Então, para que se possa minimizar essa probabilidade, somente através da motivação para o uso do preservativo. ${ }^{5}$

O uso do preservativo masculino nem sempre é a melhor alternativa para a prostituta, questão essa que muitas vezes nem pode ser discutida e/ ou negociada antes da relação sexual, se o cliente não quiser. Essa situação em que a prostituta se encontra depende da aceitação do parceiro, já que é ele que o utiliza, sendo este cliente portador de valores e iniciativas que demonstram preconceitos, e podem produzir constrangimentos à mulher, quando não as submetem a ações coercitivas ou, muitas vezes, agressivas. ${ }^{18-19}$

Essa é uma realidade presente no local do estudo, pois segundo relatos informais das prostitutas não há a disponibilidade de preservativos femininos suficientes, por este ser ainda muito caro, fazendo com que se submetam a uma negociação mais difícil com relação ao uso do preservativo. Alguns clientes aceitam usá-lo e outros não, dificultando a adoção do sexo seguro. 
O cliente que mantém uma relação fixa com uma prostituta, muitas vezes exige que não seja usado o preservativo. Assim sendo, elas recorrem ao uso de dois métodos de contracepção: a cartela de pílulas, com o objetivo de não engravidar, e o preservativo, para usar com os clientes. ${ }^{5}$

Acreditar na fidelidade, na estabilidade, no parceiro fixo, traz a sensação de sexo seguro e faz com que a prostituta decida não usar o preservativo, mesmo quando sabe da infidelidade do parceiro. ${ }^{11,19}$

O risco de contaminação das DSTs/HIV/ aids está associado a uma avaliação da própria vulnerabilidade e à identificação de comportamentos chamados de "risco" que influenciam nessa contaminação. As prostitutas, devido às condições, nas quais estão inseridas e nas quais realizam seu trabalho, encontram-se em uma situação de grande vulnerabilidade social, que expõe o indivíduo ao risco de infecção das DSTs. Muitas vezes esta mulher não apresenta condições efetivas de fazer valer seu desejo de se proteger, devido à ação de fatores externos, que é mais forte que sua capacidade de agir contra as DSTs e a aids. ${ }^{20}$

Quanto às formas de prevenção das DSTs/ $\mathrm{HIV} /$ aids, a mais citada pelas prostitutas foi o uso do preservativo. As perguntas também associam o número de parcerias sexuais e o fato de conhecer bem o parceiro como forma de prevenção. Sobre a associação do uso do preservativo ao cliente fixo, assim como o companheiro, 14 delas afirmaram que sim, que utilizam preservativo até com o companheiro e/ ou cliente fixo; nove delas que não utilizam e duas mulheres relataram que apenas às vezes. Outro aspecto destacado refere-se ao relato de uma prostituta que referiu não utilizar o preservativo, já que ambos são HIV positivo. Só às vezes (e11). Não, ele não gosta (e4). Não, pois ele tem HIV (e6).

Com base em estudos, é evidente que o preservativo somente previne as DSTs/aids se usado em todas as relações sexuais, sendo ela vaginal, oral e/ou anal. Utilizá-lo esporadicamente, não utilizá-lo, ou utilizá-lo apenas com clientes que não passam confiança, não previne o indivíduo das DSTs/aids.

Outro ponto importante e que não deve deixar de ser comentadoé a re-contaminação do HIV entre a prostituta e seu parceiro, evidenciado pela fala da e6. Mesmo ambos estando contaminados com o vírus, a proteção deve existir para que não aconteça a re-contaminação, podendo agravar assim, o quadro de ambos.
A maioria das prostitutas considera um sinal de fidelidade ao marido ou companheiro fixo a não utilização de preservativos. Deste modo o preservativo simbolizaria, para ela, a diferença entre a vida pessoal e a profissional.

As prostitutas recebem propostas que, para elas, são irrecusáveis. Clientes oferecem mais dinheiro para que os "programas" sejam realizados sem o uso de preservativos e estas, muitas vezes, aceitam praticar sexo oral desprotegido. Outras, na "empolgação", ou mesmo dominadas pelas drogas, acabam deixando de lado o preservativo no momento do sexo oral, mas que este seria usado na penetração, embora destaquem que já se expuseram por não tê-lo utilizado no sexo oral. Assim, tornam-se cada vez mais vulneráveis às DSTs. Muitas vezes essa maior "vulnerabilidade" ocorre devido às necessidades financeiras ou a episódios de violência contra a mulher, que as obrigam a ter relações sexuais desprotegidas, ou por questões relacionadas ao uso do álcool e/ou drogas pelas prostitutas ou seus clientes, ou os dois, e pelos preconceitos existentes contra essa população, por parte, tanto da sociedade, como dos clientes, contribuindo para uma baixa autoestima. ${ }^{20}$

Questionou-se entre as prostitutas acerca da existência de alguma situação em que elas desprezaram o uso do preservativo. Das 25 participantes do estudo, 14 disseram que não, que o utilizam em qualquer situação; e 11 confirmaram que sim, que mantêm relações sexuais sem preservativo em determinadas situações. Sim, quando não tem preservativo (e12). Sim, eu odeio camisinha (e7). Com o meu marido, ele não gosta de camisinha (e6). Sim, só por amor (e1).

Percebeu-se através das respostas o fator financeiro, em que a prostituta nem sempre tem o preservativo em mãos, e quando não o tem, não o utiliza. Percebeu-se também a questão cultural, em que ela ou o parceiro "não gostam" do preservativo e, por último, a questão afetiva, de confiança no parceiro estão presentes na crença de que se utilizarem o preservativo com o "marido", o "namorado", o "parceiro fixo", estarão quebrando essa relação de confiança.

Confiar no companheiro ou cliente, este ser jovem ou idoso, solteiro, casado ou viúvo, são aspectos que não devem ser considerados, principalmente quando se fala em prostituição, em uma profissão em que ocorre a venda do sexo. As pessoas que não se previnem estão sempre susceptíveis a contrair DSTs/aids. ${ }^{5}$

A ilusão é uma das violências de quem trabalha na noite. Iludir-se de que o futuro está 
apenas no casamento e que esse casamento começará na noite de trabalho, pode estimular a crença da mulher prostituta no cliente carinhoso, que tem dinheiro e que a trata bem. Isso influencia na aceitação da condição de "namorada", sendo, portanto, o preservativo, esquecido na relação. Este fato remete à idéia de que muitas garotas que não têm dinheiro guardado, têm uma mala cheia de roupa e uma cabeça cheia de ilusões. ${ }^{21}$

A utilização do preservativo deve ser prioritária na vida da prostituta, algo que faça parte da sua rotina, mas, infelizmente, isso ainda não é notório. Muitas delas relacionaram o risco de contrair DST aos "programas", nas quais existe apenas a troca de dinheiro e nenhum envolvimento emocional. Nesses casos, o preservativo está mais presente, quando se trata de atividade em que não há envolvimento afetivo e emocional.

Para análise do mundo da prostituição, foi preciso conhecer um pouco os mitos e as fantasias que são construídas em torno da sexualidade feminina, bem como a forma pela qual a própria prostituta se relaciona em suas relações sexuais (ato sexual propriamente dito), tanto profissionais (com clientes), quanto afetivas (com namorados). ${ }^{19}$ Assim, torna-se importante investigar as diferenças entre "sexo com clientes" e "sexo com namorados" a partir da ótica das profissionais, uma vez concluída a existência destas diferenças.

Outro questionamento procedido entre as prostitutas foi acerca do que elas fazem em caso de DSTs e que lugar ou quem procuram para tratamento. As respostas foram variadas. Sempre vou ao médico ou a APROCE... lá é ótimo, sempre me ajudam (e13). Farmácia (e1). Nada, não gosto de médicos (e7). Vou ao médico do posto de saúde (e2).

A maioria das prostitutas procura atendimento médico em caso de DST. É importante que um dos fatores que favorecem a cadeia de transmissão das DSTs é o tempo em que a vítima permanece infectada, sem tratamento adequado. Quanto maior o interesse em cuidar de sua saúde, menor será o número de infectados. Mais importante ainda é que a prostituta se previna e não contraia uma DST, embora estas doenças de transmissão sexual sejam realidade em suas vidas, contudo caso isto ocorra, é preciso buscar atendimento médico adequado o mais rápido possível.

O comparecimento periódico ao serviço de saúde de uma pessoa portadora de uma DST, inclusive do vírus HIV, para os exames de rotina, possibilita precisar sobre o início do tratamento, também com os antirretrovirais, ou sua eventual modificação. E um resultado mais positivo desse tratamento. $^{3}$

A cada ano cresce o número de casos de DST. Como a notificação não é compulsória, cerca de $70 \%$ das pessoas se automedicam ou procuram atendimento por profissionais não qualificados (balconistas de farmácia), algumas vezes motivados pelo sentimento de culpa e vergonha de estarem infectados. Apenas 200 mil casos por ano no Brasil foram notificados. No Ceará, foram notificados 255 casos no ano de 2004 . $^{3}$

\section{O uso de drogas}

A frequente utilização de bebidas alcoólicas e/ou drogas ilícitas é um fato concreto neste estudo. O efeito de drogas ilícitas, como maconha, cocaína e crack, ou lícitas, como cigarro e álcool, quando se está dominada pelas drogas, se prevenir torna-se algo mais complexo.

O uso de drogas lícitas e ilícitas está profundamente ligado ao cotidiano das prostitutas. Absurdamente, a grande maioria das prostitutas usa as drogas como "instrumentos de trabalho", mas, geralmente, sem perder o controle sobre o que consome. ${ }^{16}$

Outros estudos comprovam que o uso de drogas e a prostituição estão estritamente ligados, na medida em que o primeiro possibilita a entrega do corpo como mercadoria, isentando a mulher de um aprofundamento reflexivo. . $-6,8,12^{\text {A droga impõe-se }}$ por seu poder medicamentoso: poder aguentar os imperativos que a prostituição lhe proporciona.

Sobre o uso de drogas, o resultado foi unânime. Todas as prostitutas relataram que são usuárias de drogas. Sim, bebida, maconha e crack (e14). Uso muita cocaína e êxtase para agüentar vários homens numa noite (e4). Sim, principalmente quando vou para a zona (e2). Sim, sempre (e15). Sim, freqüentemente (e16).

Todas fazem uso constante de drogas, seja ela lícita e/ou ilícita. Elas estabelecem, portanto, um padrão de uso, que causa danos na saúde física e mental. Uma vez que se encontram nas ruas fazendo "programas", o consumo de drogas aparece como algo tentador e indispensável, que vai amenizar o sentimento ruim que a profissão possa causar. Uma vez vivendo na prostituição e com o uso exacerbado de drogas, torna-se muito mais difícil a liberdade em relação ao vício, pois essas duas circunstâncias se retroalimentam. Ressalta-se também que nas ruas existem aquelas que se prostituem para poder manter o vício, o que constitui 
a prática de troca de sexo para a manutenção do consumo de drogas. O dinheiro advindo da prostituição era empregado por todas as mulheres quase exclusivamente no consumo de crack. ${ }^{8}$

Pode-se afirmar que o uso de drogas em "programas" oferecidos pelas prostitutas amplia muito a vulnerabilidade para contrair ou mesmo transmitir uma ou mais DSTs/HIV/aids, pois podem diminuir a capacidade de negociação do uso de preservativos com os clientes. $\mathrm{O}$ uso de drogas nas zonas de prostituição é um problema concreto, podendo ser confirmado pelas afirmações das mulheres. Há registros constatando que a grande demanda de drogas está associada ao efeito deturpante da consciência promovido pelo álcool, cocaína e crack, no desempenho diário da profissão. As drogas são consideradas uma "ajuda" para abrandar as dificuldades encontradas no dia a dia da profissão, principalmente, como foi relatado no estudo, para que se possa "aguentar" o grande número de clientes diários.

\section{CONSIDERAÇÕES FINAIS}

Verificou-se, neste estudo, o comportamento de um grupo de prostitutas frente à prevenção das DSTs/aids. Muitas delas não utilizam o preservativo em todas as relações sexuais, e quando se fala do companheiro ou de clientes fixos, elas demonstram desconhecer o perigo diante da ausência da prevenção adequada. Estabelecem um vínculo de confiança que resultam na rejeição à própria saúde, em virtude de uma relação desprotegida.

Observou-se também que as mulheres do estudo ainda não possuem o conhecimento devido quanto às DSTs, no tocante à transmissão, aos sinais e sintomas, e como deve ser tratada. Ainda existe uma carência de informação ou de entendimento, pois a APROCE trabalha junto a essas mulheres no intuito de informá-las e ajudá-las a se protegerem das devidas doenças, e encaminhá-las, quando necessário, ao Centro de Saúde.

Os parceiros utilizam diversos argumentos para não utilizar o preservativo com a prostituta em todas as relações sexuais, como por exemplo: o desejo em não usar; relações fixas, representando confiança, dentre outras; acabam por convencer a prostituta de que somente é importante o uso do preservativo com clientes desconhecidos e/ou recentes. Portanto, elucida-se que elas ainda não têm a consciência de que a única maneira para se evitar as DSTs é através do uso adequado e sistemático do preservativo em todas as relações sexuais.
Sinalizou-se, portanto, uma realidade difícil, com um grande consumo de bebidas alcoólicas, cocaína, maconha, cigarros, crack, enfim, vários tipos de drogas possíveis. Logo, é preciso compreender o papel facilitador que as drogas e o álcool podem exercer na transmissão dessas doenças, pois notouse nas respostas que o uso ainda é diário.

Os dados do estudo permitem concluir que apesar de todas as ações educativas existentes, desenvolvidas pela APROCE, com ênfase na prevenção das DSTs / aids, esta ação ainda não está sendo suficiente. Fazem-se necessárias intervenções eficazes para a prevenção de possíveis doenças junto às prostitutas e ainda que, com o incremento do uso de preservativos, sejam obtidos resultados importantes nos programas de controle de DSTs, podendo-se reduzir em números os contaminados, diminuindo a desinformação, aumentando a educação, principalmente a conscientização sobre a prevenção apropriada, para que se possa reduzir o número de contaminações de DSTs/aids na cidade de Fortaleza.

Destarte, esta pesquisa trouxe para o conhecimento da Enfermagem uma realidade que precisa ser mais explorada e abordada, pois se trata de um contingente de pessoas que necessita de informações e apoio, em diversas áreas: prevenção de doenças sexualmente transmissíveis e outras; uso exacerbado de drogas lícitas e ilícitas; promoção da saúde; tratamento de doenças; dentre outras, podendo o enfermeiro ser um agente facilitador neste processo, se engajando nesses grupos, associações, atuando como educador em saúde.

\section{REFERÊNCIAS}

1. Vianna A, Lacerda P. Direitos e políticas sexuais no Brasil: o panorama atual. $1^{\mathrm{a}}$ ed. Rio de Janeiro (RJ): Centro latino-americano em Sexualidade e Direitos Humanos/ Instituto de Medicina Social; 2004. Coleção Documentos.

2. Carvalho FT, Piccinini CA. Aspectos históricos do feminino e do maternal e a infecção pelo HIV em mulheres. Ciênc Saúde Coletiva. 2008 Nov-Dez; 13(6):1889-98.

3. Ministério da Saúde (BR). Boletim Epidemiológico [Internet]. Brasília (DF): Ministério da Saúde [acesso 2008 Mai 05]. Disponível em http:/ / portal. saude.gov.br/portal/aplicações/noticias_detalhe. cfm?co_seq_noticia $=39177$.

4. Ministério da Saúde (BR). Boletim Epidemiológico [Internet]. Brasília (DF): Ministério da Saúde; 2009 [acesso 2009 Out 14]. Disponível em http:/ / www. aids.gov.br/data/pages/lumis9a49113dptbrie.htm. 
5. Moura ADA. Uso do preservativo por profissionais do sexo no município de Limoeiro do Norte - CE [monografia]. Fortaleza (CE): Escola de Saúde Pública do Ceará; 2002.

6. Moura ADA, Pinheiro AKB, Barroso MGT. Realidade vivenciada e atividades educativas com prostitutas: subsídios para a prática de enfermagem. Esc Anna Nery Rev Enferm. 2009 Jul-Set; 13(3):602-8.

7. Ministério da Saúde (BR). Doenças Sexualmente Transmissíveis. Brasília (DF): Ministério da Saúde; 2006.

8. Nunes ELG, Andrade AG. Adolescentes em situação de rua: prostituição, drogas e HIV/aids em Santo André, Brasil. Psicol Soc. 2009 Jan-Abr; 21(1):45-54.

9. Polit DF, Beck CT, Hungler BP. Pesquisa em enfermagem: métodos, avaliação e utilização. $5^{\mathrm{a}} \mathrm{ed}$. Porto Alegre (RS): Artmed; 2004.

10. Minayo MCS, Deslandes SF, Neto OC, Gomes R. Pesquisa social: teoria, métodos e criatividade. Petrópolis (RJ): Vozes; 1994.

11. Aquino PS, Nicolau AIO, Moura ERF, Pinheiro AKB. Perfil sociodemográfico e comportamento sexual de prostitutas de Fortaleza-CE. Texto Contexto Enferm. 2008 Jul-Set; 17(3):427-34.

12. Moura ADA. Educação em saúde com prostitutas na prevenção das DSTs/aids: reflexões à luz de Paulo Freire [dissertação]. Fortaleza (CE): Universidade Federal do Ceará, Programa de Pós-Graduação em Enfermagem; 2007.

13. Simon CP, Silva RC, Paiva V. Prostituição juvenil feminina e a prevenção da aids em Ribeirão Preto, SP. Rev Saúde Pública. 2002 Ago; 36(4):82-7.
14. Associação das Prostitutas do Ceará (CE). Casa della Solidarietá - Rete Radie Resch. Fortaleza (CE): APROCE; 2006.

15. Gomes R, Minayo MCS, Fontoura HA. A prostituição infantil sob a ótica da sociedade e da saúde. Rev Saúde Pública. 1999; 33(22):171-9.

16. Ministério da Saúde (BR). Políticas e diretrizes de prevenção das DSTs/AIDS entre mulheres. Brasília (DF): Ministério da Saúde; 2003. (Série Manuais $\mathrm{n}^{\mathrm{o} 57) \text {. }}$

17. Rossi L. Prevenção das DSTs/aids e a prostituição feminina no Brasil [internet]. 1998 [acesso 2008 Set 09]. Disponível em http://www.aids.gov.br/cgeral/ong/prostf.htm.

18. Madureira VSF, Trentini M. Da utilização do preservativo masculino à prevenção de DSTs/aids. Cienc Saúde Coletiva. 2008 Nov-Dez; 13(6):1807-16.

19. Eluda K, Bosi MLM, Cunha AJLA, Trajman A. Quando um não quer, dois não brigam: um estudo sobre o não uso constante do preservativo masculino por adolescentes do município de Rio de Janeiro, Brasil. Cad Saúde Pública. 2006 Ago; 22(8):1671-80.

20. Ferraz EA, Souza CT, Souza LM, Costa N. Travestis profissionais do sexo e HIV/aids: conhecimento, opiniões e atitudes [Internet]. 2006 [acesso 2008 set 09]. Disponível em http://www.cedeplar.ufmg. br/seminarios/seminario_diamantina/2006/ D06A012.pdf.

21. Oltramari LC, Camargo BV. Representações sociais de profissionais do sexo sobre prevenção de doenças sexualmente transmissíveis e contracepção. Psicol Teor Prat. 2004 Dez-Jun; 6(2):75-87. 